\title{
A Case of Ischemic Cerebellar Stroke with Alcoholic Cardiomyopathy
}

\section{Alkolik Kardiyomiyopatili Bir İskemik Serebellar İnme Olgusu}

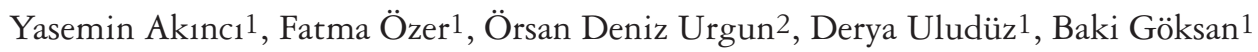 \\ 1 Istanbul University Cerrahpasa Faculty of Medicine, Department of Neurology, Istanbul, Turkey \\ 2University of Health Sciences, Adana Numune Training and Research Hospital, Clinic of Cardiology, Adana, Turkey
}

Keywords: Alcohol, cardiomyopathy, stroke

Anahtar Kelimeler: Alkol, kardiyomiyopati, inme

\section{Introduction}

Excessive alcohol consumption increases the risk of hemorrhagic and ischemic strokes through various mechanisms. Alcoholic cardiomyopathy (ACM), a subtype of dilated cardiomyopathy, may cause cardioembolic brain infarction. ACM is responsible for one-third of non-ischemic dilated cardiomyopathies and is the most common etiology of nonischemic cardiomyopathies in Western countries that have high rates of alcohol consumption. Like other diseases caused by alcohol, ACM is more common among young and middle-aged males and mortality rates are higher among males $(1,2)$. Here, we describe a case of acute cerebellar infarction due to ACM, which was diagnosed and treated in our institution. We report this case to draw attention to the importance of detecting and treating ACM associated with excessive alcohol consumption.

\section{Case Report}

A man aged 56 years was admitted to our clinic with a 2-day history of increasing weakness, loss of balance, dizziness, nausea, and vomiting. He had smoked one pack of cigarettes a day for 10 years, but quit smoking in 2006 after being diagnosed as having asthma. His neurologic examination revealed ataxic gait, a positive Romberg test, and tandem incompetence. No pathologic findings, other than a grade $2 / 6$ systolic murmur heard in the mitral focus were observed. Systemic examination revealed high arterial blood pressure. Computerized tomography and diffusion-weighted-imaging confirmed the diagnosis of ischemic stroke. We noted a mild shift in the fourth ventricle as a result of edema caused by the lesion, but this was not classified as hydrocephalus (Figure 1, 2).

Intraventricular conduction delay, sinus rhythm, left ventricular (LV) hypertrophy, and left atrium dilatation were monitored using a standard 12-lead electrocardiogram. Blood and urine tests revealed no significant pathology. The patient was diagnosed as having acute cerebellar ischemia and treatment with anti-aggregant and anti-edema medications was started. Intracranial and cervical magnetic resonance angiography findings were normal. The left ventricle was globally hypokinetic, the LV ejection fraction was $35 \%$, the left atrial size was $41 \mathrm{~mm}$, and the LV end-diastolic and systolic diameters were 43 and 37 $\mathrm{mm}$, respectively. A transthoracic echocardiography examination (TTE) revealed LV stage 2 diastolic dysfunction and LV mass increase. No arrhythmia was detected on the 24-hour Holter rhythm monitor.

A more detailed history revealed that the patient had consumed 60-100 g of alcohol per day $\geq 4$ days per week for the past 33 years, and he had consumed alcohol every day for the

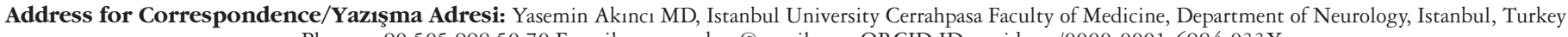
Phone: +90 5059985070 E-mail: yasemnaknc@gmail.com ORCID ID: orcid.org/0000-0001-6984-033X

Received/Geliş Tarihi: 13.07.2016 Accepted/Kabul Tarihi: 28.03.2017

${ }^{\circ}$ Copyright 2017 by Turkish Neurological Society

Turkish Journal of Neurology published by Galenos Publishing House. 
last 2 months, suggesting that he was consuming at least 220 $\mathrm{g}$ of ethanol per day. Coronary angiography was performed to investigate the etiology of the cardiomyopathy. The findings were normal, and we concluded that his condition was the result of alcohol consumption. The patient was monitored and treated with an angiotensin-converting enzyme (ACE) inhibitor, a beta-adrenergic blocker, and anticoagulant, and was provided with detailed information about abstaining from alcohol.

At his last follow-up visit at 3 months, the patient had completely ceased alcohol consumption. TTE examination revealed that the LV wall motion dysfunction had regressed, the LV ejection fraction was $50 \%$, and his neurologic examination was completely normal.

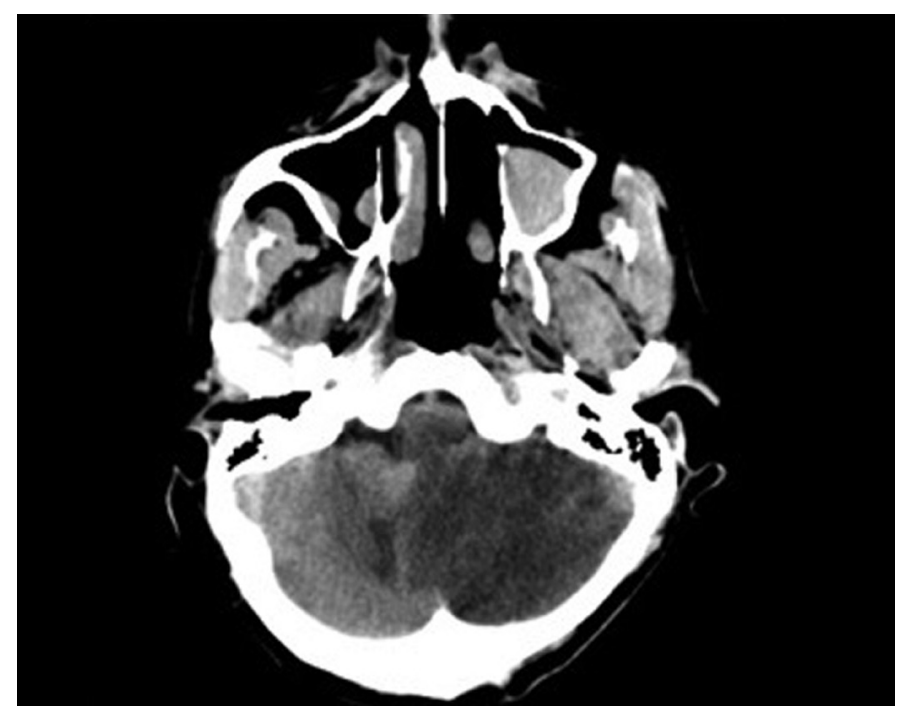

Figure 1. Computed tomography demonsrates hypodense lesions in both cerebellar hemispheres (left > right), two days after onset of symtomps

\section{Discussion}

The relationship between alcohol consumption and systemic disease is complex and influenced by factors including the amount of alcohol consumed, culture, socioeconomic status, genetics, sex, and age. Consumption of small amounts of alcohol (up to one drink per day for females and one or two drinks per day for males) are reported to decrease the risk of mortality, coronary artery disease, congestive heart failure, and stroke, particularly red wine because of the high flavonoid content of grapes. Conversely, excessive alcohol intake increases the risk of arterial hypertension, cardiomyopathy, and hemorrhagic and ischemic stroke (3).

Heavy alcohol consumption can provoke cardiogenic cerebral emboli via thrombus formations caused by ACM and arrhythmia. A previous study found that consumption of more than $80 \mathrm{~g}$ of alcohol per day for 10 years caused cardiomyopathy; however, familial and genetic predisposition may also play a role (4).

ACM is characterized by LV dilatation, normal or decreased LV wall thickness, increased LV mass, and a low LV ejection fraction $(<40 \%)$ in advanced cases. Clinical diagnosis is generally made in heavy drinkers with myocardial dysfunction in the absence of other identified causes (5). Ethanol intake $\geq 24 \mathrm{~g}$ per day in females and $\geq 36 \mathrm{~g}$ per day in males has been found to cause hypertension; therefore, hypertension frequently contributes to LV dysfunction in cases of cardiomyopathy (6). Excessive alcohol intake is responsible for one-third of newly emerging atrial fibrillation cases, and malignant ventricular arrhythmias are common when the LV ejection fraction is $<40 \%(7,8)$. However, arrhythmia was not detected in our patient.

Our patient's treatment regime included discontinuation of alcohol consumption and symptomatic treatment for heart failure. Administration of ACE inhibitors or angiotensin receptor blockers and $\beta$-adrenergic blockers is essential for patients with an LV ejection fraction $<40 \%$. Other diuretic and cardiac glycosides may be necessary depending on other signs and symptoms (9). Previous studies have suggested that patients with ACM have a lower
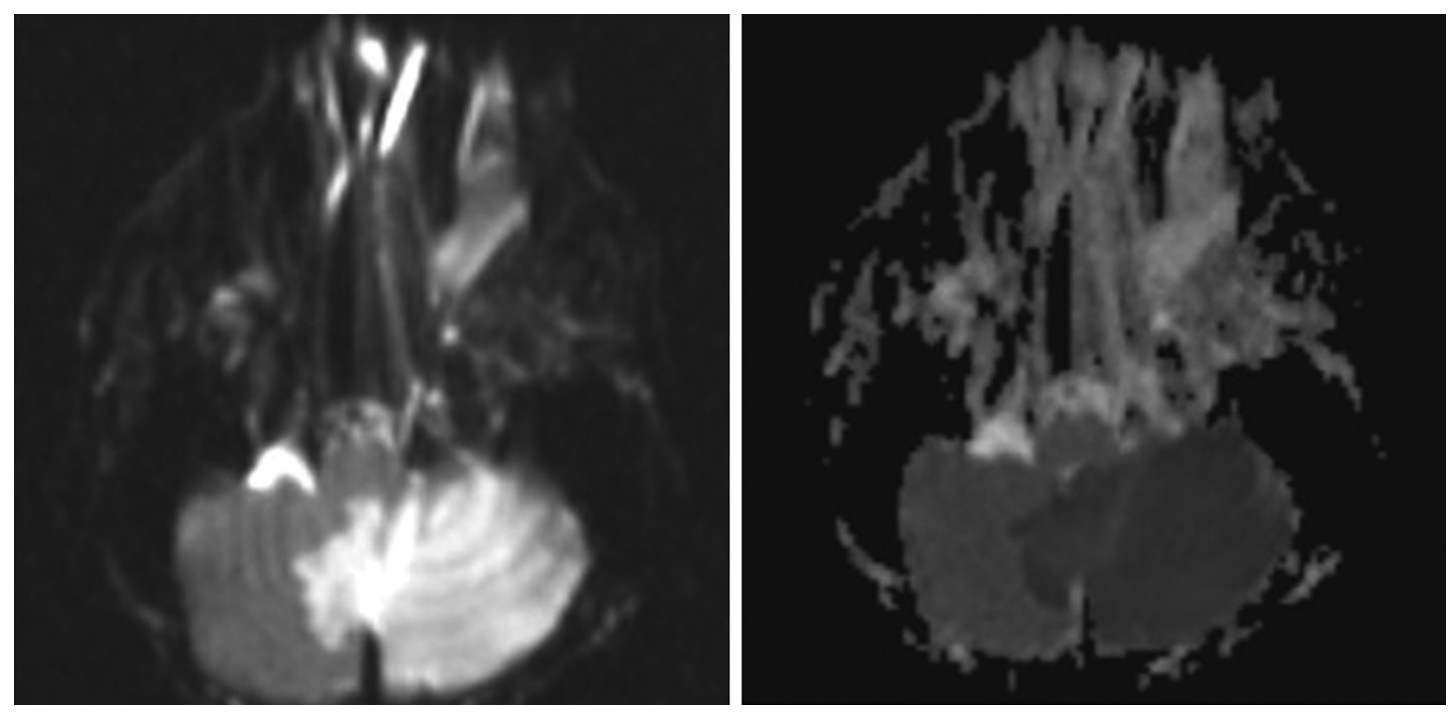

Figure 2. Axial diffusion weighted imaging and apparent diffusion coefficient map. Lesions in both cerebellar hemispheres consistent with acute ischaemic infarction with edema and compression of the fourth ventricle. 
mortality rate than those with idiopathic dilated cardiomyopathy if they abstain from alcohol. However, abstinence is challenging for patients with ACM, and Fauchier et al. (10) found that treatment outcomes for patients with ACM were not better than for patients with idiopathic dilated cardiomyopathy; this suggests that an aggressive approach to alcohol cessation is crucial for disease management in patients with ACM.

According to the Organization for Economic Cooperation and Development (OECD) health report, adults (aged $\geq 15$ years) in Turkey consumed approximately $1.5 \mathrm{~L}$ of alcohol per capita in 2014. Turkey is the second country consuming the least alcohol among OECD countries in terms of adult alcohol consumption. However, substantially high unrecorded alcohol intake underscoring the fact that alcohol consumption is a significant public health problem in Turkey (11). Thus, taking time to routinely and carefully document patients' alcohol consumption history is important because early detection and treatment can prevent dangerous complications.

\section{Ethics}

Informed Consent: Consent form was filled out by all participants.

Peer-review: Externally peer-reviewed.

\section{Authorship Contributions}

Surgical and Medical Practices: Y.A., F.Ö., Ö.D.U., D.U., Concept: Y.A., Ö.D.U., D.U., B.G., Design: Y.A., Ö.D.U., D.U., B.G., Data Collection or Processing: Y.A., Analysis or Interpretation: Y.A., B.G., Literature Search: Y.A., Writing: Y.A., Ö.D.U., D.U.

Conflict of Interest: No conflict of interest was declared by the authors.

Financial Disclosure: The authors declared that this study received no financial support.

\section{References}

1. Hillbom M. Alcohol consumption and stroke: benefits and risks. Alcohol Clin Exp Res 1998;22(Suppl 7):352-358.

2. Guzzo-Merello G, Cobo-Marcos M, Gallego-Delgado M, Garcia-Pavia P. Alcoholic cardiomyopathy. World J Cardiol 2014;26:771-781.

3. O'Keefe JH, Bhatti SK, Bajwa A, DiNicolantonio JJ, Lavie CJ. Alcohol and cardiovascular health: the dose makes the poison... or the remedy. Mayo Clin Proc 2014;89:382-393.

4. Balk AH. Dilated cardiomyopathy, are a few drinks allowed? Eur Heart J 2000;21:267-269.

5. Piano MR, Phillips SA. Alcoholic cardiomyopathy: Pathophysiologic insights. Cardiovasc Toxicol 2014;14:291-308.

6. Camargo CA, Rimm EB. Epidemiological research on moderate alcohol consumption and blood pressure. In: Zakhari S, Wassef M (eds). Alcohol and the Cardiovascular System, NIAAA Research Monograph. Washington: 1996:43.

7. Lip GY, Beevers DG, Singh SP, Watson RD. ABC of atrial fibrillation: Aetiology, pathophysiology, and clinical features. BMJ 1995;311:14251428.

8. Guzzo-Merello G, Dominguez F, González-López E, Cobo-Marcos M, GomezBueno M, Fernandez-Lozano I, Millan I, Segovia J, Alonso-Pulpon L, GarciaPavia P. Malignant ventricular arrhythmias in alcoholic cardiomyopathy. Int J Cardiol 2015;199:99-105.

9. Yancy CW, Jessup M, Bozkurt B, Butler J, Casey DE Jr, Drazner MH, Fonarow GC, Geraci SA, Horwich T, Januzzi JL, Johnson MR, Kasper EK, Levy WC, Masoudi FA, McBride PE, McMurray JJ, Mitchell JE, Peterson PN, Riegel B, Sam F, Stevenson LW, Tang WH, Tsai EJ, Wilkoff BL; American College of Cardiology Foundation; American Heart Association Task Force on Practice Guidelines. 2013 ACCF/AHA guideline for the management of heart failure: a report of the American College of Cardiology Foundation/American Heart Association Task Force on Practice Guidelines. J Am Coll Cardiol 2013; 62:148-239.

10. Fauchier L, Babuty D, Poret P. Comparison of long-term outcome of alcoholic and idiopathic dilated cardiomyopathy. Eur Heart J 2000;21:306-314.

11. OECD (2015), Tackling Harmful Alcohol Use: Economics and Public Health Policy, OECD Publishing. http//dx.doi.org/10.1787/9789264181069-en 